\title{
On-pump versus off-pump: It's all about the grafts!
}

\author{
Paul Kurlansky, MD
}

From the Department of Surgery, Columbia University, New York, NY.

Disclosures: Author has nothing to disclose with regard to commercial support.

Received for publication Oct 17, 2016; accepted for publication Oct 17, 2016; available ahead of print Nov 1, 2016.

Address for reprints: Paul Kurlansky, MD, Black Building 210, 650 168th St, New York, NY 10032 (E-mail:

Pk2245@cumc.columbia.edu).

J Thorac Cardiovasc Surg 2017;153:298-9

$0022-5223 / \$ 36.00$

Copyright (c 2016 by The American Association for Thoracic Surgery

http://dx.doi.org/10.1016/j.jtcvs.2016.10.006

Originally proposed as a less-invasive form of revascularization, off-pump coronary artery bypass (OPCAB) surgery promised to reduce morbidity, decrease resource use, and provide a better surgical option for high-risk patients. Early enthusiasm has yielded to a more balanced approach. Metaanalyses of prospective randomized control trials suggest a benefit in reducing perioperative stroke and potentially
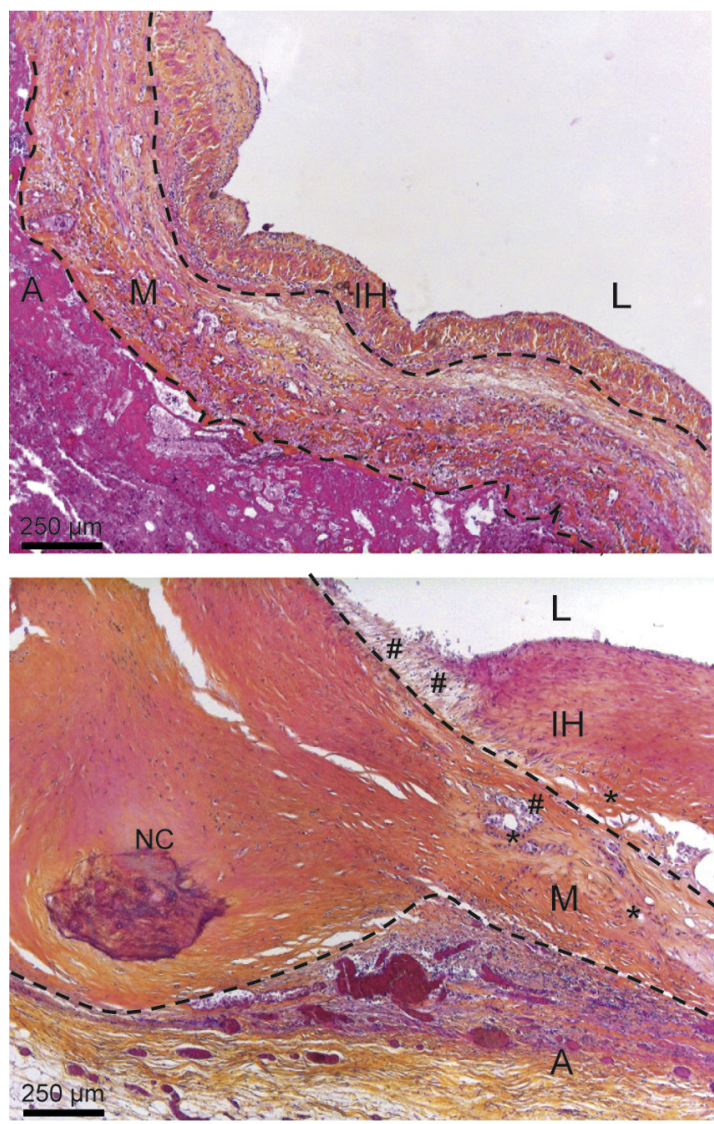

FIGURE 1. Macroscopic and microscopic views of failed human vein graft. $A$, Adventitia; $M$, media; $I H$, intimal hyperplasia; $L$, lumen; $N C$, necrotic core; \#foam cells; *neovessels. Reprinted by permission from Macmillan Publishers Ltd: de Vries MR, Simons KH, Jukema JW, Braun J, Quax PHA. Vein graft failure: from pathophysiology to clinical outcomes. Nat Rev Cardiol. 2016;13:451-70.

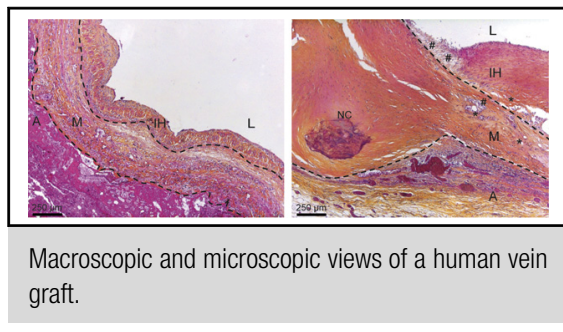

Central Message

MAG provides comparable perioperative outcomes and improved long-term survival in both on-pump and off-pump coronary revascularization.

See Article page 300

renal impairment, ${ }^{1,2}$ whereas longer-term studies suggest decreased graft patency and increased need for revascularization. ${ }^{3,4}$ Despite an abundance of evidence supporting the benefits of multiple arterial grafting (MAG) (Figure 1), ${ }^{5,6}$ the literature has been remarkably silent on the issue of how this approach may affect the outcomes of on-pump coronary artery bypass versus OPCAB. Benedetto and colleagues ${ }^{7}$ exploration of just this issue provides a welcome first step in filling the void.

In a retrospective single-center analysis of 12,633 patients undergoing isolated coronary artery bypass grafting extending over a 20-year period, Benedetto and colleagues ${ }^{7}$ found that, in comparable patients, patients undergoing on-pump and off-pump MAG had a $20 \%$ improved long-term survival. Perioperative results were comparable, and the benefit of MAG disappeared in the absence of complete revascularization. The authors are to be commended for their diligence in data collection and follow-up. Ironically, the greatest weaknesses of this study may be some of its greatest strengths. As a singlecenter study, the findings may not be applicable to other surgical environments. However, the multiplicity of surgeons and surgical skills within this center provide an interesting cross-section of surgical experience. Indeed, both MAG and OPCAB appear to have declined in more recent years with shifts in surgical personnel. More important, when comparing surgical techniques, the singlecenter experience tends to minimize variations in the manifold details that comprise patient care, differences that remain hidden and difficult to account for in multicenter studies. Therefore, the observed differences in outcome are more likely to be technique related rather than center related. The limitation of sample size tends 
to force Benedetto and colleagues ${ }^{7}$ to extend the study period, introducing a potential time-related bias. The conundrum of outcomes research is that one must follow patients long enough to observe time-related effects. However, by the time sufficient years have elapsed for adequate evaluation, medicine has changed. Care of the surgical patient, interventional alternatives, and medical therapy evolve over the course of patient accrual, and the most recent study participants may not have sufficient years or numbers to adequately address currently relevant patient care. Nonetheless, the Bristol experience with both $\mathrm{OPCAB}$ and arterial grafting has been robust, and the 20 -year study period, with careful adjustment in analytic models for year of surgery, permits an interesting window into the cumulative OPCAB experience that may actually permit a more definitive answer to the study objectives. Last, as noted by Benedetto and colleagues, ${ }^{7}$ the retrospective approach limited the ability to fully control for all variables, especially those unidentified by the data, which may affect patient selection. Nonetheless, inclusive registry data actually may better reflect clinical practice. ${ }^{8}$ With the skillful use of advanced statistical modeling, Benedetto and colleagues ${ }^{7}$ may well have produced findings more rather than less readily applicable in clinical practice.

\section{References}

1. Kowalewski M, Pawliszak W, Malvindi PG, Bokszanski MP, Perlinski D Raffa GM, et al. Off-pump coronary artery bypass grafting improves short-term outcomes in high-risk patients compared with on-pump coronary artery bypass grafting: meta-analysis. J Thorac Cardiovasc Surg. 2016;151:60-77.e1-58.

2. Parissis H, Lau MC, Parissis M, Lampridis S, Graham V, Al-Saudi R, et al. Current randomized control trials, observational studies and meta analysis in off-pump coronary surgery. J Cardiothorac Surg. 2015;10:185.

3. Deppe AC, Arbash W, Kuhn EW, Slottosch I, Scherner M, Liakopoulos OJ, et al. Current evidence of coronary artery bypass grafting off-pump versus on-pump: a systematic review with meta-analysis of over 16,900 patients investigated in randomized controlled trials. Eur J Cardiothorac Surg. 2016;49:1031-41.

4. Houlind K, Fenger-Gron M, Holme SJ, Kjeldsen BJ, Madsen SN, Rasmussen BS et al; DOORS Study Group. Graft patency after off-pump coronary artery bypass surgery is inferior even with identical heparinization protocols: results from the Danish On-pump Versus Off-pump Randomization Study (DOORS). J Thorac Cardiovasc Surg. 2014;148:1812-9.e2.

5. Yi G, Shine B, Rehman SM, Altman DG, Taggart DP. Effect of bilateral internal mammary artery grafts on long-term survival: a meta-analysis approach. Circulation. 2014;130:539-45.

6. Gaudino M, Taggart D, Suma H, Puskas JD, Crea F, Massetti M. The choice of conduits in coronary artery bypass surgery. J Am Coll Cardiol. 2015;66:1729-37.

7. Benedetto U, Caputo M, Mariscalco G, Gaudino M, Chivasso P, Bryan A, et al Impact of multiple arterial grafts in off-pump and on-pump coronary artery bypass surgery. J Thorac Cardiovasc Surg. 2017;153:300-9.e6.

8. Mack MJ. Clinical trials versus registries in coronary revascularization: which are more relevant? Curr Opin Cardiol. 2007;22:524-8. 